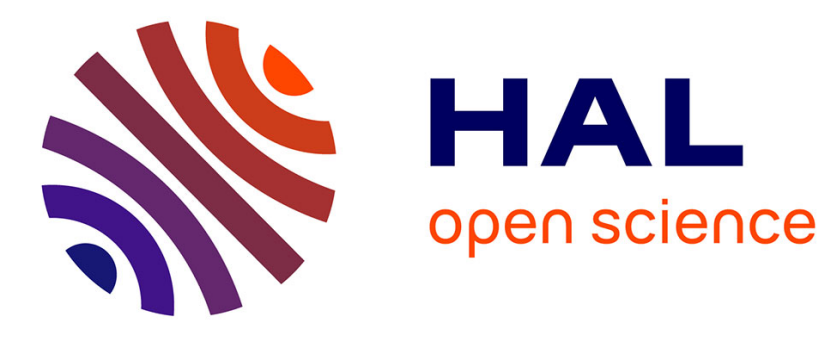

\title{
New elements concerning the Mullins effect: A thermomechanical analysis
}

Jose Ricardo Samaca Martinez, Jean-Benoit Le Cam, Xavier Balandraud, Evelyne Toussaint, Julien Caillard

\section{To cite this version:}

Jose Ricardo Samaca Martinez, Jean-Benoit Le Cam, Xavier Balandraud, Evelyne Toussaint, Julien Caillard. New elements concerning the Mullins effect: A thermomechanical analysis. European Polymer Journal, 2014, 55, pp.98-107. 10.1016/j.eurpolymj.2014.03.014 · hal-01063256

\section{HAL Id: hal-01063256 https://hal.science/hal-01063256}

Submitted on 7 May 2020

HAL is a multi-disciplinary open access archive for the deposit and dissemination of scientific research documents, whether they are published or not. The documents may come from teaching and research institutions in France or abroad, or from public or private research centers.
L'archive ouverte pluridisciplinaire HAL, est destinée au dépôt et à la diffusion de documents scientifiques de niveau recherche, publiés ou non, émanant des établissements d'enseignement et de recherche français ou étrangers, des laboratoires publics ou privés.

\section{(c)(1)}

Distributed under a Creative Commons Attribution| 4.0 International License 


\title{
New elements concerning the Mullins effect: a thermomechanical analysis
}

\author{
José Ricardo Samaca Martinez, ${ }^{a, b, c}$ Jean-Benoît Le Cam, ${ }^{\mathrm{d}, 1}$ \\ Xavier Balandraud, ${ }^{\mathrm{e}, \mathrm{b}}$ Evelyne Toussaint, ${ }^{\mathrm{a}, \mathrm{b}}$ Julien Caillard ${ }^{\mathrm{c}}$ \\ ${ }^{a}$ Clermont Université, Université Blaise Pascal, Institut Pascal, BP 10448, 63000 \\ Clermont-Ferrand, France \\ ${ }^{\mathrm{b}}$ CNRS, UMR 6602, Institut Pascal, 63171 Aubière, France \\ ${ }^{\mathrm{c}}$ MICHELIN, CERL Ladoux, 63040 Clermont-Ferrand, France \\ ' UNIVERSITÉ DE RENNES 1, Institut de Physique de Rennes UMR 6251 - \\ CNRS/Université de Rennes 1, DÈpartement MÈcanique et Verres, Campus de \\ Beaulieu, 35042 Rennes, France

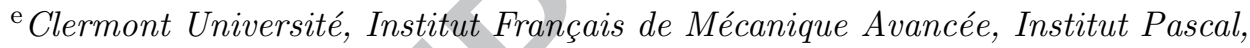 \\ BP 10448, 63000 Clermont-Ferrand, France
}

\begin{abstract}
This paper investigates thermomechanical effects in carbon black-filled rubbers under cyclic uniaxial tensile loading at ambient temperature. More especially, it focuses on the calorimetric response of rubbers during stress softening, which occurs during the first mechanical cycles. Two materials were studied, natural rubber (NR) and styrene butadiene rubber (SBR), which are respectively crystallizable and noncrystallizable under stress. Temperature changes were first measured by infrared thermography. Then heat sources produced or absorbed by the material due to deformation processes were deduced from these temperature changes by using the
\end{abstract}


heat equation. Heat source variations during each mechanical cycle were analyzed. In particular, the mechanical dissipation produced in each cycle was deduced. For both materials, the relative contribution to mechanical dissipation of dissipative mechanisms involved in stress softening and viscosity was determined. One of the main results is that, for both materials, the mechanical dissipation due to the Mullins effect is not produced only during the first cycle. In the second cycle, the mechanical dissipation due to the Mullins effect is not negligible: it corresponds to up to $35 \%$ (compared to the first cycle) for the highest stretch ratio tested in the present study. Moreover, mechanical dissipation due to the Mullins effect increases less significantly at high maximum stretch ratios.

Key words: Rubber-like materials, Mullins effect, mechanical dissipation, thermal response, heat source identification.

\section{Introduction}

One of the main phenomena in the mechanics of rubber-like materials dates from the observation by Bouasse in 1903 (see Ref. Bouasse and Carriere. (1903)) of stress softening after the first mechanical load. Later, this phenomenon was studied more precisely by Mullins in 1948 (see Ref. Mullins (1948)) and was then referred to as "the Mullins effect". Considering a cyclic uniaxial tensile test, this effect can be defined by five main features (see Ref. Diani et al. (2009)):

- most of the softening is obtained after the first load;

- a few cycles are necessary to stabilize the mechanical response;

$\overline{1}$ Corresponding author jean-benoit.lecam@univ-rennes1.fr Fax : (+33) 223236111 
- softening appears for stretch ratios lower than or equal to the maximum stretch ratio previously applied;

- when the stretch ratio exceeds the maximum stretch ratio previously applied, the material stress-strain response returns on the same path as the monotonous uniaxial tension test stress-strain response after a transition, which increases with the amount of strain;

- softening increases progressively with the increasing maximum stretch ratio.

Despite the numerous studies reported in the literature since the work of these pioneers, no consensus has been found on the physical origin of the Mullins effect. Among the phenomena described, one can cite bond rupture (see Ref. Blanchard and Parkinson (1952)), chain rupture (see Ref. Bueche (1960)), chain slipping (see Ref. Houwink (1956)), chain disentanglement (see Ref. Hamed and Hatfield (1989)), filler-cluster breakdown (see Refs. Klüppel and Schramm (2000); Kraus et al. (1966)) and network rearrangement (see Refs. Marckmann et al. (2002); Diani et al. (2006)).

Up to now, the Mullins effect has only been investigated from a mechanical point of view, while its thermal and calorimetric signatures might provide information of paramount importance. In this study, we propose to measure the temperature changes during the deformation of rubbers by using infrared thermography (IRT). IRT is a full thermal field measurement technique that provides accurate information about temperature variations at the surface of a specimen subjected to influences that can differ in nature (mechanical, thermal, chemical). It can be noted that in the tests performed in the present study, stress softening in rubbers is accompanied by heat production and heat exchanges with the outside. Moreover, during the first cycles, the tempera- 
ture evolution is not stabilized. Consequently, the analysis of the temperature does not provide a clear understanding of the thermomechanical phenomena. For this reason, temperature variation cannot easily be used to study the thermal effects accompanying stress softening. This is the reason why we use the framework of the thermodynamics of irreversible processes (TIP) and the heat diffusion equation to measure the total heat source produced or absorbed by the material. The heat source is composed of several terms. Under certain hypotheses, the part due to thermomechanical cosoftened filled styrene-butadiene rubber (see Ref. Samaca Martinez et al. (2013c)) for further information. This approach is applied in the present study in order to identify the calorimetric signature of the Mullins effect, i.e. the mechanical dissipation due to stress softening.

The paper is divided into two parts. The first part presents the experimental set-up and the second presents the results, analysis and discussion. Concluding remarks close the paper.

\section{Experimental Setup}

\subsection{Material and specimen geometry}

The materials considered here were natural rubber (NR) and styrene-butadiene rubber (SBR), both filled with the same amount of carbon black $50 \mathrm{phr}^{2}$.

$\overline{2 \text { part }}$ per hundred of rubber in weight 
They are respectively denoted NR50 and SBR50 in the following. Apart from the macromolecules themselves, the compounds had the same chemical composition (see Table 1). The degree of cross-linking density is $6.5 \times 10^{-5} \mathrm{~mol}_{\mathrm{cm}} \mathrm{cm}^{-3}$ for NR50 and $8.3 \times 10^{-5} \mathrm{mol.cm}{ }^{-3}$ for SBR50. It should be noted that only the NR50 formulation is subject to stress-induced crystallization: the characteristic stretch ratios at which crystallization and crystallite melting occur are denoted by $\lambda_{c}$ and $\lambda_{m}$ and are close to 1.8 and 1.6, respectively. Thin dumbbell-shaped specimens were used. They were $5 \mathrm{~mm}$ in width, $10 \mathrm{~mm}$ in length and $1.4 \mathrm{~mm}$ in thickness. The width was chosen to ensure the homogeneity of the mechanical fields during uniaxial tensile tests, i.e. a uniaxial tension state.

\subsection{Loading conditions}

The mechanical tests corresponded to cyclic uniaxial tensile loadings. They were applied under prescribed displacement using an INSTRON 5543 testing machine with a load cell capacity of $500 N$. The signal shape was triangular in order to ensure a constant strain rate during loading and unloading. Indeed, most filled rubbers exhibit viscosity; it is therefore more relevant not to change the strain rate during material deformation. The loading rate and the nominal

strain rate $(\dot{\lambda})$ were equal to $\pm 300 \mathrm{~mm} / \mathrm{min}$ and $\pm 0.5 \mathrm{~s}^{-1}$, respectively. The tests corresponded to 4 series composed of uniaxial mechanical cycles, at four different maximum stretch ratios. The number of cycles for each maximum stretch ratio was chosen in such a way that the mechanical response was stabilized for the last cycle. This number was equal to 5 for NR50 and 3 for SBR50. The following maximum stretch ratios were chosen (see Figure 1): 
- for NR50, the four maximum stretch ratios denoted by $\lambda_{1}, \lambda_{2}, \lambda_{3}, \lambda_{4}$ were chosen equal to $1.4,2,4$ and 6 , respectively. $\lambda_{1}$ was chosen as lower than $\lambda_{c} \cdot \lambda_{2}$ was close to $\lambda_{c} \cdot \lambda_{3}$ and $\lambda_{4}$ were higher than $\lambda_{c}\left(\lambda_{4}\right.$ was close to the failure stretch ratio).

- for SBR50, the four maximum stretch ratios $\lambda_{1}, \lambda_{2}, \lambda_{3}, \lambda_{4}$ were chosen equal to $2,3,4$ and 4.5 , respectively.

Note that, for the two formulations, the maximum stretch ratios $\lambda_{i}, i=1 . .4$ chosen were different, due to the fact that the stretches at failure of the materials were different (6.3 for NR50 and 4.8 for SBR50).

Temperature field measurements were performed using a Cedip Jade IIIMWIR infrared camera. The principal features of this camera are presented in Table 2. The calibration of the camera detectors was performed using a black body and a Non-Uniformity Correction (NUC) procedure. A two-point calibration was applied. The IR camera was switched on four hours before the beginning of the experiments in order to ensure that its internal temperature was stabilized before performing the calibration and the measurement. Internal temperature stabilization of the IR camera is necessary to avoid any measurement drift during the tests.

During measurements, external disturbances were reduced by using a black box surrounding the specimen, featuring a small window in such way that the IR camera could observe the gauge zone of the specimen. The thermal quantity extracted from the measurement was the mean temperature change over a small zone of $5 \times 5 \mathrm{px}\left(1 \mathrm{~mm}^{2}\right)$ at the centre of the specimen. This quantity was obtained by subtracting the initial temperature from the current one, after applying a suitable movement compensation technique (see Ref. Samaca 
Martinez et al. (2013a)) to track this small zone during the test.

\subsection{Brief reminder of the heat source calculation}

It is now well known that temperature is not the most relevant quantity to consider in the study of phenomena involved during the deformation of material. Indeed, stress softening can be accompanied by heat exchanges with the specimen outside (non-adiabaticity of the thermomechanical evolution). For this reason, temperature variation cannot be used to study the calorific phenomena accompanying stress softening. Temperature is the consequence of the heat produced or absorbed by the material due to stretching, but also of the heat diffusion in the specimen and of the heat exchanges with the outside. The calculation of the heat sources from the temperature changes is briefly presented below.

Assuming that the heat source fields are homogeneous in the specimen, the heat diffusion equation can be written in a '0D' formulation (see Ref. Chrysochoos (1995)). In the present study, this approach is relevant because the tests are assumed to be homogeneous in terms of strain and stress fields. Moreover,

rubbers have very low thermal diffusivity, which leads to nearly homogeneous temperature fields. Thus the heat equation can be written as follows :

$$
\rho C_{E, V_{k}}\left(\dot{\theta}+\frac{\theta}{\tau}\right)=s
$$

where $\rho$ is the density, $C_{E, V_{k}}$ is the specific heat at constant $E$ and $V_{k}$ (state variables), $\theta$ is the difference between the current and the initial temperature of 
the material, $\tau$ is a time constant characterizing the heat exchanges between the specimen and its environment, i.e. the ambient air and the jaws of the testing machine.

In practice, the constant $\tau$ is experimentally assessed by identification from a simple test of natural return to room temperature. It can be noted that $\tau$ must be measured for each testing configuration (material, specimen geometry, environment in terms of ambient air and jaws of the testing machine). Some comments can be added concerning tests that are performed on rubber materials. Large deformations lead to a variation in the specimen thickness, leading also to a change in the value of $\tau$. In this case, a linear expression of $\tau$ as a function of the stretch ratio $\lambda$ has been experimentally determined (see Refs. Samaca Martinez et al. (2013b,c)):

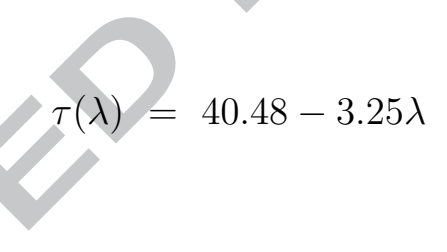

It should be noted that the function used was the same whatever the material considered because the product of the density by the heat capacity does not change from one compound to another, the initial thickness being the same.

The right-hand side of equation (1) represents the total heat source $s$ produced by the material itself. It can be divided into two terms:

- mechanical dissipation $d_{1}$ (or intrinsic dissipation): this positive quantity corresponds to the heat source which is produced due to mechanical irreversibilities;

- thermomechanical coupling heat sources: these correspond to the couplings 
between the temperature and the other state variables.

Let us conclude with some considerations on units. The heat source $s$ is expressed in $W \cdot m^{-3}$. However, it is generally useful to divide this quantity by $\rho C_{E, V_{k}}$, so that equation (1) writes:

$$
\dot{\theta}+\frac{\theta}{\tau}=\frac{s}{\rho C_{E, V_{k}}}
$$

The quantity $s / \rho C_{E, V_{k}}$ is expressed in ${ }^{\circ} \mathrm{C} / \mathrm{s}$. It corresponds to the temperature rate that would be obtained in an adiabatic case, i.e. for an infinite value of $\tau$. In the rest of this paper, the term "heat source" will also be used for this quantity $s / \rho C_{E, V_{k}}$. As already indicated above, the term "heat" must be distinguished from "heat source". The heat is the temporal integration of the heat sources. It is expressed in $J \cdot m^{-3}$, and in ${ }^{\circ} C$ when divided by $\rho C_{E, V_{k}}$.

\section{Results}

In this section, the results obtained during cyclic tests are reported for the two filled rubbers considered. First, the mechanical responses are presented and analyzed. Second, the response in terms of heat source evolution during the tests is given for each compound. Third, the calorimetric signature of the deformation processes is detailed for each maximum stretch ratio tested, in order to analyze the mechanical dissipation and, in fine, to extract the part of the mechanical dissipation which is due to Mullins softening mechanisms. 


\subsection{Mechanical response}

The mechanical responses obtained for NR50 and SBR50 are presented in Figures $2 \mathrm{a}$ and $2 \mathrm{~b}$, respectively. These figures present the nominal stress, defined as the force per initial surface ratio, versus the stretch ratio. The following comments can be made:

- as expected, the mechanical cycles had an important effect on the mechanical response, in the sense that stress softening was observed between the cycles. Most of the softening was obtained after the first load of the series, whatever the maximum stretch ratio applied. The maximum nominal stress considerably decreased between the two first cycles, approximately $30 \%$ for NR50 and $12 \%$ for SBR50. These values have been calculated using the maximum stress during cycle 1 et 2 for the two last series of cycles (for $\lambda_{3}$ and $\left.\lambda_{4}\right)$;

- a hysteresis loop was observed for both filled materials. The mechanical response of NR50 exhibited a larger hysteresis loop;

- a residual strain was observed. It reached $80 \%$ and $35 \%$ at the end of the test for NR50 and SBR50, respectively;

- when the stretch ratio exceeded the maximum stretch ratio previously applied, the gap (in terms of the stretch ratio) to return to the maximum stress previously obtained was larger for NR50. It should be recalled that, compared to SBR50, NR50 exhibited a higher residual strain. Moreover, the curve of the first load, obtained for higher maximum stretch ratios, did not join what would be the monotonous tensile curve. 


\subsection{Calorimetric response}

Figures $3 \mathrm{a}$ and $3 \mathrm{~b}$ present the calorimetric responses obtained for each compound during the cyclic tests. These figures, which give the heat sources in ${ }^{\circ} \mathrm{C} / \mathrm{s}$ versus time, enable some discussion on the different calorific phenomena involved during the first cycles of each series. Several comments can be drawn from these figures:

- for both compounds, an increase in the stretch ratio applied during loading induced an increase in the heat source, which is the signature of entropic elasticity (see Refs. Samaca Martinez et al. (2013a,c));

- the heat source was lower for stretch ratios inferior or equal to the maximum stretch ratio previously applied;

- when the stretch ratio exceeded the maximum stretch ratio previously applied, the calorimetric response greatly increased. This result closely resembles that of the mechanical response;

- for a given maximum stretch ratio (for instance $\lambda=4$ ), the heat source produced by NR50 was larger than that produced by SBR50.

\subsubsection{Calorimetric response in filled non-crystallizable rubbers (SBR50)}

In this section, heat sources obtained with SBR50 are analyzed qualitatively for each series of maximum stretch ratios applied.

- Series \#1 (three cycles at $\left.\lambda_{1}=2\right)$, Figure 4(a) - During the loading phases, the heat source was positive and increased with the stretch ratio. The heat sources produced during the first loading were slightly larger than those produced during the two following loadings. The heat sources produced dur- 
ing loading were stabilized from the second cycle (similar evolution during the second and third loading phases). During the three unloading phases, the heat sources were negative (heat absorbed by the material). The three curves can nearly be superimposed, meaning that the number of mechanical cycles had no significant effect on the deformation processes during unloading. Consequently, this highlights that a larger mechanical dissipation was produced during the first cycle: this can be seen as damage associated with stress softening. This is in good agreement with the fact that a larger hysteresis loop was observed for the first cycle in the mechanical response;

- Series \#2 (three cycles at $\lambda_{2}=3$ ), Figure 4(b) - During the loading phases, when the stretch ratio exceeded the maximum stretch ratio previously applied (in this case $\lambda=2$ ), a high increase in heat source production was observed. This result strongly echoes that obtained with the mechanical response. From the third cycle, the heat sources produced during the loading phases evolved similarly during the following cycles (not reported here), meaning that the calorimetric signature of the Mullins effect is mainly observed between the first and second loads. As previously observed for the lowest maximum stretch ratio $\left(\lambda_{1}\right)$, the curves can be superimposed during the unloading phases;

- Series \#3 (three cycles at $\left.\lambda_{3}=4\right)$, Figure 4(c) - Results are similar to the previous ones: when the stretch ratio exceeded the maximum stretch ratio previously applied (in this case $\lambda=3$ ), a high increase in heat source production was observed. Nevertheless, a difference was observed for stretch ratios superior to 3.7: the heat source decreased instead of increasing continuously, before increasing again. Heat continued to be produced (the heat source value remained positive), but at a lower rate. During unloading, the shapes of the heat source profiles absorbed are not similar. In fact, the heat 
source absorbed at the beginning of the unloading phases decreases with the number of cycles;

- Series \#4 (three cycles at $\lambda_{4}=4.5$ ), Figure 4(d) - The phenomena are similar to those described above. However, it can be noted that during the first loading, at $\lambda$ equal to approximately 4 , the heat source decreased quasiinstantaneously (by about $0.5^{\circ} \mathrm{C} / \mathrm{s}$ ), before increasing again. This was previously observed at lambda $=3.7$ for the previous maximum stretch ratio applied. This phenomenon seems to depend on the maximum stretch ratio. The understanding of such a phenomenon requires further investigations that were not carried out in this study. For instance, this phenomenon could be explained by the increase in the permanent set between series \#3 and series \#4.

To summarize these results, we recall through Figure 5 the interpretation framework that we recently proposed in (Ref. Samaca Martinez et al. (2013c)). This figure gives the schematic response for an entropic and viscous material which is damaged during loading, typically during the first mechanical loading for which stress softening is observed. This diagram enables us to evaluate the relative contribution of different phenomena in the calorimetric response, and more especially to evaluate the mechanical dissipation due to the Mullins effect and that due to viscosity. It can be noted that the curves are not represented at the lowest strains, because their shape strongly depends on the phenomena involved in the material deformation. For instance viscosity may induce a (positive) heat source as soon as the material is stretched. In other words, the curves do not systematically start from zero. 


\subsubsection{Calorimetric response in filled crystallizable rubbers (NR50)}

For NR50, only the cycles for last two series $\left(\lambda_{3}\right.$ and $\left.\lambda_{4}\right)$ are presented, due to the fact that a significant permanent set (compared to the maximum stretch ratio applied) was observed for the first two maximum stretch ratios applied. This permanent set induced buckling which disturbed the temperature measurement. Consequently, we have not calculated heat sources for these cycles. It should be noted that, for series \#3 and series \#4, the maximum stretch ratio applied is superior to that at which crystallization begins. The following comments can be drawn:

- Series \#3 (five cycles at $\lambda_{3}=4$ ), Figure 6(a) - During the first loading phase, the heat source was positive and increased quasi-linearly with the stretch ratio. The heat source variations for loading and unloading were not symmetrical in a cycle. Such a result cannot be explained only by the effects of entropic coupling and viscosity. Other observations can be made: the heat source produced during the first loading was much larger than that produced during the following four loadings. The heat sources produced during loading were stabilized from the fifth cycle. During unloading, the (negative) heat source profiles seem to be superimposed, meaning that the number of mechanical cycles had no significant effect on the deformation processes during unloading. Moreover, the unloading curve shape shows that the rate of heat source is not constant: a change in the slope sign is observed at a stretch ratio lower than that at which the increase in the heat source was observed during loading (for the stabilized cycle at the same maximum stretch ratio level). Thus, the highest heat absorption was not obtained at the beginning of the unloading phase. This clearly highlights 
that the effects of entropic couplings are not preponderant. By comparing the calorimetric responses of unfilled styrene butadiene (see Ref. Samaca Martinez et al. (2013c)) and natural rubbers (see Ref. Samaca Martinez et al. (2013b)), we previously showed that such a response shape is due to stress-induced crystallization. A major difference with SBR50 is the change in the curve shape during the loading phases. Indeed, the heat source was positive and increased quasi-linearly with the stretch ratio, and the following cycles exhibited a sudden increase in the heat source produced. This could be explained by the fact that mechanical dissipation due to the Mullins effect masks the contribution of stress-induced crystallization during the first cycle. Consequently, the high increase in heat source production could correspond to the occurrence of crystallization. Moreover, the stretch ratio at which this phenomenon is observed does not change during the cycles for a given maximum stretch ratio. This is in close agreement with previous results reported in the literature (see Refs. Le Cam (2010); Marchal (2006)).

- Series \#4 (five cycles at $\lambda_{4}=6$ ), Figure 6(b) - Results were similar to those obtained previously. The only difference is the high increase in the heat source produced after the first loading, which is attributed to stress-induced crystallization and occurs at the highest stretch ratios. This seems to indicate that stress-induced crystallization can be influenced by the Mullins effect. Indeed, a shift is observed in the stretch ratio at which there is a strong increase in the heat source due to crystallization at the second load, if the applied maximum stretch ratio is increased. Figure 7 shows that this increase in heat source production was observed for quite the same nominal stress level, here 3.3 MPa. However, this does not prove that stress governs crystallization. In our opinion, it is more probably due to filler network reor- 
ganization, which tends to minimize and to homogenize the effects of strain amplification by fillers. Thus, the softened material crystallizes at higher stretch ratio levels, meaning that the crystallinity is lower from the second cycle at a given maximum stretch ratio. This fits well with results recently reported by H. Zhang (Zhang et al. (2013)) et K. Brüning (Brüning et al. (2012)).

Finally, it is difficult to compare curves obtained for the first and the following maximum stretch ratios applied if the material crystallizes during loading. Indeed, if the high increase in the heat source produced corresponds to the beginning of crystallization, the crystallization stretch ratio increases with the maximum stretch ratio (actually from the second cycle of the series). It is reasonable to consider that the heat produced by crystallization is therefore greater at the first cycle. This could explain why it appears clearly in Figure 6(b) that the heat absorbed is a little higher for the first unloading than for the following ones.

\subsection{Calculation of mechanical dissipation corresponding to the Mullins effect from the calorimetric response}

Classically, the hysteresis loop in terms of the strain-stress relationship is considered to account for mechanical dissipation, so that for instance mechanical dissipation due to viscosity is deduced from the measurement of the hysteresis loop area. In the opinion of the authors, this is not the optimum approach. Indeed, the hysteresis area is not systematically induced by mechanical dissipation. In unfilled natural rubber, the hysteresis loop is observed only when the material is crystallizing. We have recently shown that in this case, the 
heat source balance during a cycle shows that no mechanical dissipation is produced (see Ref. Samaca Martinez et al. (2013b)), and consequently the area of the hysteresis loop cannot only be associated with mechanical dissipation. Moreover, the hysteresis loop is not only related to mechanical dissipation but also to thermal dissipation. As the heat source calculated from the heat diffusion equation is not dependent on thermal dissipation, we consider that this is another argument in favour of calculating mechanical dissipation from the calorimetric response.

In the present study, the temporal integration of the mechanical dissipation is calculated for each mechanical cycle. This quantity will be still named 'mechanical dissipation' for the sake of simplicity in the following. It will be designated by $<d_{1}>\left(\right.$ in $\left.{ }^{\circ} C\right)$. Equation (4) gives the calculation of the mechanical dissipation for a given mechanical cycle whose loading is performed between $t=t_{0}$ and $t=t_{1}$, and unloading between $t=t_{1}$ and $t=t_{2}$ :

$$
<d_{1}>=<d_{1_{\text {Mullins }}}>+<d_{1_{\text {viscosity }}}>=\int_{t_{0}}^{t_{1}} s_{\text {load }} d t-\int_{t_{1}}^{t_{2}}\left|s_{\text {unload }}\right| d t
$$

It should be noted that, in equation $(4),<d_{1_{\text {viscosity }}}>$ is the sum of the dissipation due to viscosity during both loading and unloading (see Figure 5).

As several cycles are applied at a given maximum stretch ratio until response stabilization, the mechanical dissipation due to the Mullins effect is deduced as follows: 


$$
<d_{1_{\text {Mullins }}}>=<d_{1}>_{\text {cycle 1 }}-<d_{1}>_{\text {last cycle }}
$$

Here, we assume that at any cycle:

$$
<d_{1_{\text {viscosity }}}>=<d_{1}>_{\text {last cycle }}
$$

Let us to recall that the last cycle is the third one for $S B R 50$ and the fifth one for NR50. This approach enables us to compare model prediction with experimental results, but does not allow us to attribute the total mechanical dissipation as a function of the maximum stretch ratio reached if several series of mechanical cycles are applied at increasing maximum stretch ratios. This is the reason why the mechanical dissipation at any cycle is calculated by taking into account the mechanical dissipation occurring at the previous series of cycles, if any:

$$
<d_{1}^{\lambda_{i}}>_{j}=<d_{1_{\text {Mullins }}^{i}}^{i}>_{j}+<d_{1_{\text {viscosity }}^{i}}^{i}>_{j}+\sum_{n=1}^{i-1}<d_{1_{\text {Mullins }}^{n}}^{n}>_{j}
$$

where:

- $i$ is the number of the series;

- $j$ is the number of the cycle in the series;

- $<d_{1}^{\lambda_{i}}>_{j}$ is the total heat dissipated at the considered cycle number $j$ at $\lambda_{i}$

- $<d_{1_{\text {Mullins }}^{i}}^{i}>_{j}$ is the dissipation induced by stress softening;

- $<d_{1_{\text {viscosity }}}^{i}>_{j}$ is the mechanical dissipation due to viscous phenomena obtained over the stabilized cycle at the considered maximum stretch ratio. 
For each cycle, from the first to the stabilized one, the total mechanical dissipation was calculated, as well as the mechanical dissipation due to the Mullins effect at the first and second cycles. Results obtained for SBR50 and NR50 are presented in Tables 3 and 4, respectively. Mechanical dissipation due to the Mullins effect is denoted $<d_{1}(M)>$ in these tables.

As expected, the Mullins effect is higher between the first and second cycles. The higher the maximum stretch ratio level reached, the higher the mechanical dissipation due to the Mullins effect. At the highest stretch ratios, the percentage of mechanical dissipation due to the Mullins effect tends to stabilize.

Figure 8 shows the mechanical dissipation in percent for each cycle versus the maximum applied stretch ratio in both materials. The mechanical dissipation due to the Mullins effect obtained over the second cycle is not negligible in both materials (up to $35 \%$ for highest levels). In SBR, the mechanical dissipation due to stress softening is neglected from the third cycle (we consider $<d_{1}(M)>=0$ for the third cycle), while we consider that five cycles are necessary in NR. In the case of NR, which is crystallizable under strain, the interpretation must be nuanced by several observations, in particular to define the total mechanical dissipation and consequently what the meaning of the calculation of the mechanical dissipation due to stress softening could be:

after several cycles at increasing maximum stretch ratios, the first cycle of a higher maximum stretch ratio never undergone before by the material does not join the first monotonous response;

- the calorific activity due to the crystallization/melting process could differ between the first and the following cycles. Typically, the crystallinity maximum is attained at the end of the first loading. 


\section{Conclusion}

This study focuses on the calorimetric signature of mechanisms of deformation and damage involved in the stress softening of filled rubbers. More generally, this work is the calorimetric counterpart of "mechanical" studies dealing with the Mullins effect, whose thermomechanical analysis has never been performed before. Thermal variation was measured by means of infrared thermography and was used to calculate heat sources by using the heat equation. Energy balances performed during each cycle enabled us to identify mechanical dissipation due to viscosity and to mechanisms involved in stress softening. The total mechanical dissipation corresponding to the Mullins effect was calculated for each cycle from the calorimetric response. One of the main results shows that the mechanical dissipation due to the Mullins effect at the second cycle is not negligible for both materials (up to $35 \%$ for the highest stretch ratios). Moreover, the mechanical dissipation due to the Mullins effect increases less significantly at high stretch ratios, from the second series of cycles in SBR and from the third series of cycles in NR. In NR, stress softening may affect the crystallization process by increasing the stretch ratio at the beginning of the crystallization. To conclude, this work opens a new route to a more efficient validation of constitutive models dedicated to the Mullins effect, by providing the calorimetric signature of stress softening, i.e. the corresponding mechanical dissipation. 


\section{Acknowledgements}

The authors would like to thank the "Manufacture Française des pneuma-

tiques Michelin" for supporting this study. We also thank D. Berghezan for the fructuous discussions. 


\section{References}

Bouasse, H.; Carriere., Z. Annales de la faculte des sciences de Toulouse 1903, $5,257-283$.

Mullins, L. Rubber Chemistry and Technology 1948, 21, 281-300.

Diani, J.; Fayolle, B.; Gilormini, P. European Polymer Journal 2009, 45, 601612.

Blanchard, A. F.; Parkinson, D. Rubber Chemistry and Technology 1952, 52, $799-812$.

Bueche, F.; Journal of Applied Polymer Science 1960, 4, 107-114.

Houwink, R. Rubber Chemistry and Technology 1956, 29, 888-893.

Hamed, G. R.; Hatfield, S. Rubber Chemistry and Technology 1989, 143-156.

Klüppel, M.; Schramm, M. Macromolecular Theory and Simulations 2000, 9, $742-754$.

Kraus, G.; Childers, C.; Rollman, K. Journal of Applied Polymer Science 1966, 10, 229-240.

Diani, J.; Brieu, M.; Gilormini, P. International Journal of Solids and Structures 2006, 43, 3044-3056.

Marckmann, G.; Verron, E.; Gornet, L.; Chagnon, G.; Charrier, P.; Fort, P. Journal of the Mechanics and Physics of Solids 2002, 50, 2011-2028.

Samaca Martinez, J. R.; Le Cam, J.-B.; Balandraud, X.; Toussaint, E.; Caillard, J. Polymer testing 2013 32, 835 - 841.

Samaca Martinez, J. R.; Le Cam, J.-B.; Balandraud, X.; Toussaint, E.; Caillard, J. Polymer 2013 54, 2717 - 2726.

Boccara, N. In. PUF coll. SUP, 1968.

Nguyen, Q.; Germain, P.; Suquet, P. J Appl Sci 1983, 50, 1010-1020.

Chrysochoos, A.; Louche, H. Int J Eng Sci 2000, 38, 1759-1788. 
Chrysochoos, A. In. Colloque Photomécanique, 1995, pp 201-211.

Samaca Martinez, J. R.; Le Cam, J.-B.; Balandraud, X.; Toussaint, E.; Caillard, J. Polymer 2013 54, 2727 - 2736.

Le Cam, J.-B. Rubber chemistry and technology 2010, 83, 247-269.

Marchal, J. Ph.D. thesis, 2006.

Zhang, H.; Scholz, A. K.; Merckel, Y.; Brieu, M.; Berghezan, D.; Kramer, E. J.; Creton, C. Journal of Polymer Science 2013, 51, 1125-1138.

Brüning, K.; Schneider, K.; Roth, S. V.; Heinrich, G. Macromolecules 2012, 45, 7914-7919. 


\section{List of Tables}

1 Chemical composition in parts per hundred rubber (phr).

$2 \quad$ IR camera parameters.

3 Total mechanical dissipation and mechanical dissipation due to the Mullins effect for the three cycles at each series of maximum applied stretch ratios in SBR50.

4 Total mechanical dissipation and mechanical dissipation due to the Mullins effect for the three cycles at each series of maximum applied stretch ratios in NR50. 
Table 1

Chemical composition in parts per hundred rubber (phr).

\begin{tabular}{ccc} 
Ingredient & NR50 & SBR50 \\
\hline NR & 100 & \\
SBR & & 100 \\
Carbon black $N 347$ & 50 & 50 \\
Antioxidant $6 P P D$ & 1.9 & 1.9 \\
Stearic acid & 2 & 2 \\
Zinc oxide $Z n O$ & 2.5 & 2.5 \\
Accelerator $C B S$ & 1.6 & 1.6 \\
Sulfur solution $2 H$ & 1.6 & 1.6 \\
\hline
\end{tabular}


Table 2

IR camera parameters.

\begin{tabular}{ll}
\hline Parameters & Values \\
\hline
\end{tabular}

Thermal resolution $\left(\left[5-40{ }^{\circ} \mathrm{C}\right]\right) \quad 20 \mathrm{mK}$

Focal plane array $\quad 320 \times 240$ pixels

Wavelength range $\quad 3.5-5 \mu m$

Integration time $\quad 1500 \mu \mathrm{s}$

Acquisition frequency

$147 \mathrm{~Hz}$ 


\section{ACCEPTED MANUSCRIPT}

Table 3

Total mechanical dissipation and mechanical dissipation due to the Mullins effect

for the three cycles at each series of maximum applied stretch ratios in SBR50.

\begin{tabular}{|c|c|c|c|c|c|c|}
\hline & \multicolumn{3}{|c|}{ series \#1 } & \multicolumn{3}{|c|}{ series \#2 } \\
\hline & $\begin{array}{c}\text { Total }<d_{1}> \\
{\left[{ }^{\circ} \mathrm{C}\right]}\end{array}$ & $\begin{array}{c}<d_{1}(M)> \\
{\left[{ }^{\circ} C\right]}\end{array}$ & $\begin{array}{c}<d_{1}(M)> \\
{[\%]}\end{array}$ & $\begin{array}{c}\text { Total }<d_{1}> \\
{\left[{ }^{\circ} \mathrm{C}\right]}\end{array}$ & $\begin{array}{c}<d_{1}(M)> \\
{\left[{ }^{\circ} \mathrm{C}\right]}\end{array}$ & $\begin{array}{c}<d_{1}(M)> \\
{[\%]}\end{array}$ \\
\hline Cycle 1 & 0.37 & 0.18 & 48.6 & 1.69 & 1.27 & 75.1 \\
\hline Cycle 2 & 0.20 & 0.01 & 5.0 & 0.58 & 0.16 & 27.6 \\
\hline Cycle 3 & 0.19 & 0.00 & 0.0 & 0.42 & 0.00 & 0.0 \\
\hline & & series \#3 & & \multicolumn{3}{|c|}{ series \#4 } \\
\hline & Total $<a$ & $<d_{1}(M)>$ & $<d_{1}(M)>$ & Total $<d_{1}>$ & $<d_{1}(M)>$ & $<d_{1}(M)>$ \\
\hline & {$\left[{ }^{\circ} \mathrm{C}\right]$} & {$\left[{ }^{\circ} \mathrm{C}\right]$} & {$[\%]$} & {$\left[{ }^{\circ} \mathrm{C}\right]$} & {$\left[{ }^{\circ} \mathrm{C}\right]$} & {$[\%]$} \\
\hline Cycle 1 & 4.78 & 3.98 & 83.3 & 6.60 & 5.67 & 85.9 \\
\hline Cycle 2 & 1.25 & 0.44 & 35.2 & 1.43 & 0.51 & 35.6 \\
\hline Cycle 3 & 0.80 & 0.00 & 0.00 & 0.93 & 0.00 & 0.0 \\
\hline
\end{tabular}


Table 4

Total mechanical dissipation and mechanical dissipation due to the Mullins effect for the three cycles at each series of maximum applied stretch ratios in NR50.

\begin{tabular}{|c|c|c|c|c|c|c|}
\hline & \multicolumn{3}{|c|}{ series \#3 } & \multicolumn{3}{|c|}{ series \#4 } \\
\hline & $\begin{array}{c}\text { Total }<d_{1}> \\
{\left[{ }^{\circ} \mathrm{C}\right]}\end{array}$ & $\begin{array}{c}<d_{1}(M)> \\
{\left[{ }^{\circ} C\right]}\end{array}$ & $\begin{array}{c}<d_{1}(M)> \\
{[\%]}\end{array}$ & $\begin{array}{c}\text { Total }<d_{1}> \\
{\left[{ }^{\circ} \mathrm{C}\right]}\end{array}$ & $\begin{array}{c}<d_{1}(M)> \\
{\left[{ }^{\circ} \mathrm{C}\right]}\end{array}$ & $\begin{array}{c}d_{1}(M)> \\
{[\%]}\end{array}$ \\
\hline Cycle 1 & 3.44 & 2.42 & 70.3 & 11.37 & 8.66 & 76.1 \\
\hline Cycle 2 & 1.42 & 0.39 & 27.5 & 4.13 & 1.42 & 34.4 \\
\hline Cycle 3 & 1.23 & 0.21 & 17.1 & 3.21 & 0.50 & 15.6 \\
\hline Cycle 4 & 1.12 & 0.09 & 8.0 & 2.94 & 0.23 & 7.8 \\
\hline Cycle 5 & 1.03 & 0.00 & 0.0 & 2.71 & 0.00 & 0.0 \\
\hline
\end{tabular}




\section{List of Figures}

$1 \quad$ Mechanical loading conditions

2 Mechanical cycles for four increasing maximum stretch ratios

3 Heat source evolution

4 Calorimetrical response obtained with SBR50 for the four maximum stretch ratios tested: $\lambda_{1}=2$ (Figure $\left.4(\mathrm{a})\right), \lambda_{2}=3$ (Figure $4(\mathrm{~b})), \lambda_{3}=4($ Figure $4(\mathrm{c}))$ and $\lambda_{4}=4.5($ Figure $4(\mathrm{~d}))$

5 Schematic evolution: heat source versus stretch ratio for entropic behaviour with the Mullins effect and viscosity

6 Calorimetric response obtained with NR50 for the last two maximum stretch ratios tested: $\lambda_{3}=4$ (Figure $6(\mathrm{a})$ ) and $\lambda_{4}=6($ Figure $6(\mathrm{~b}))$

7 Beginning of the crystallization phenomenon in both mechanical and calorimetrical response

8 Mechanical dissipation in percent for each cycle versus the maximum applied stretch ratio in filled SBR and NR 


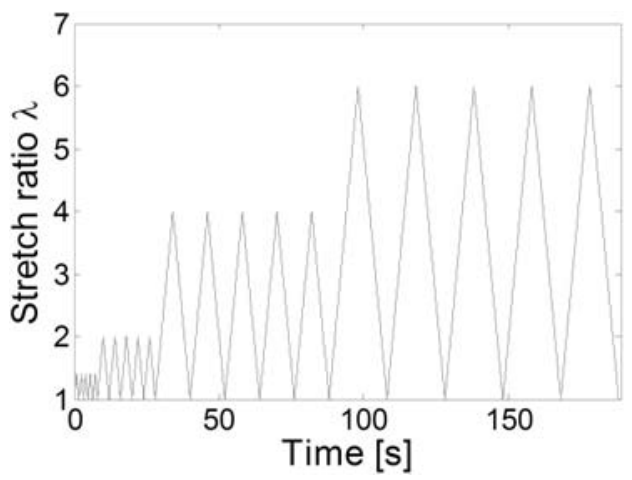

(a) NR50

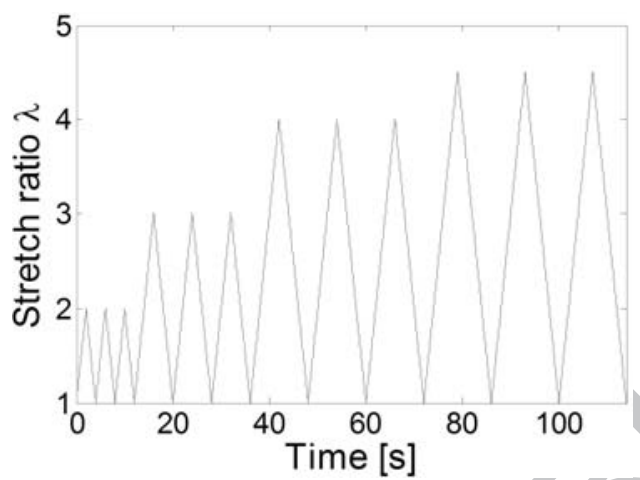

(b) $S B R 50$

Fig. 1. Mechanical loading conditions 


\section{ACCEPTED MANUSCRIPT}



(a) NR50

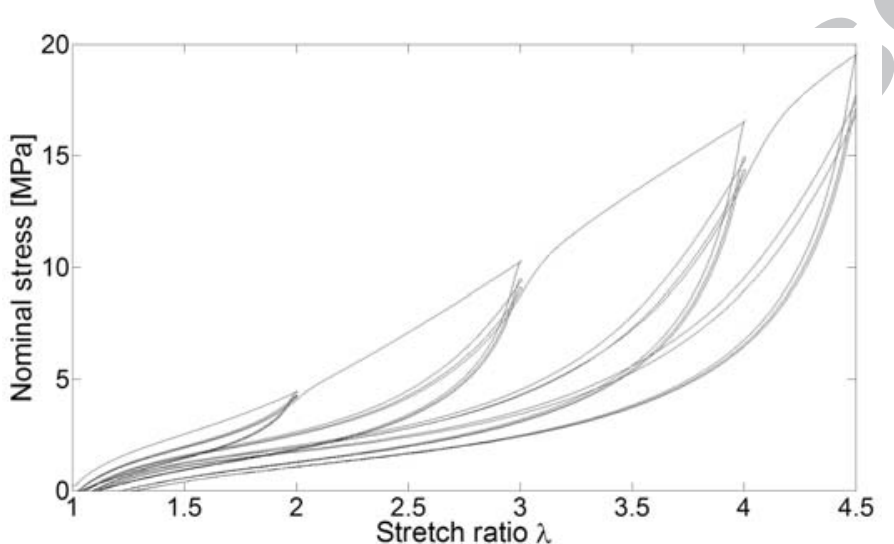

(b) $S B R 50$

Fig. 2. Mechanical cycles for four increasing maximum stretch ratios 


\section{ACCEPTED MANUSCRIPT}
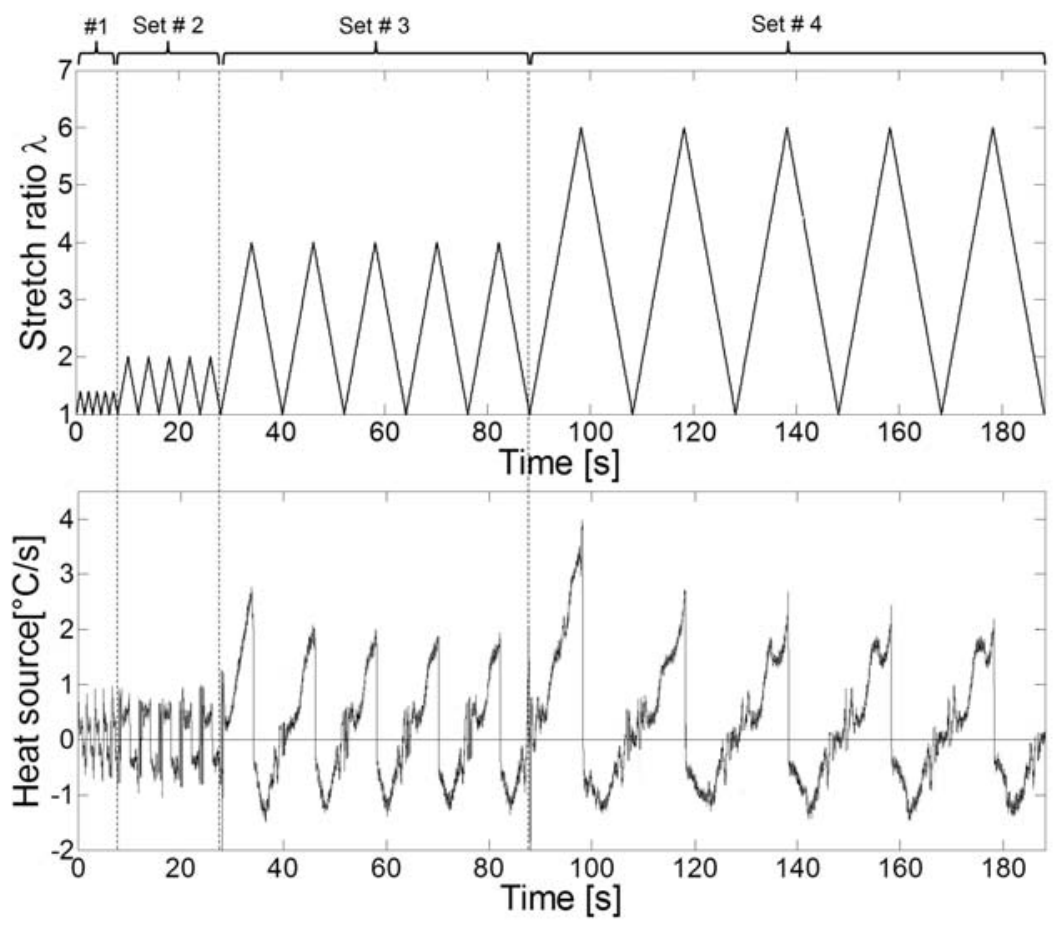

(a) NR50
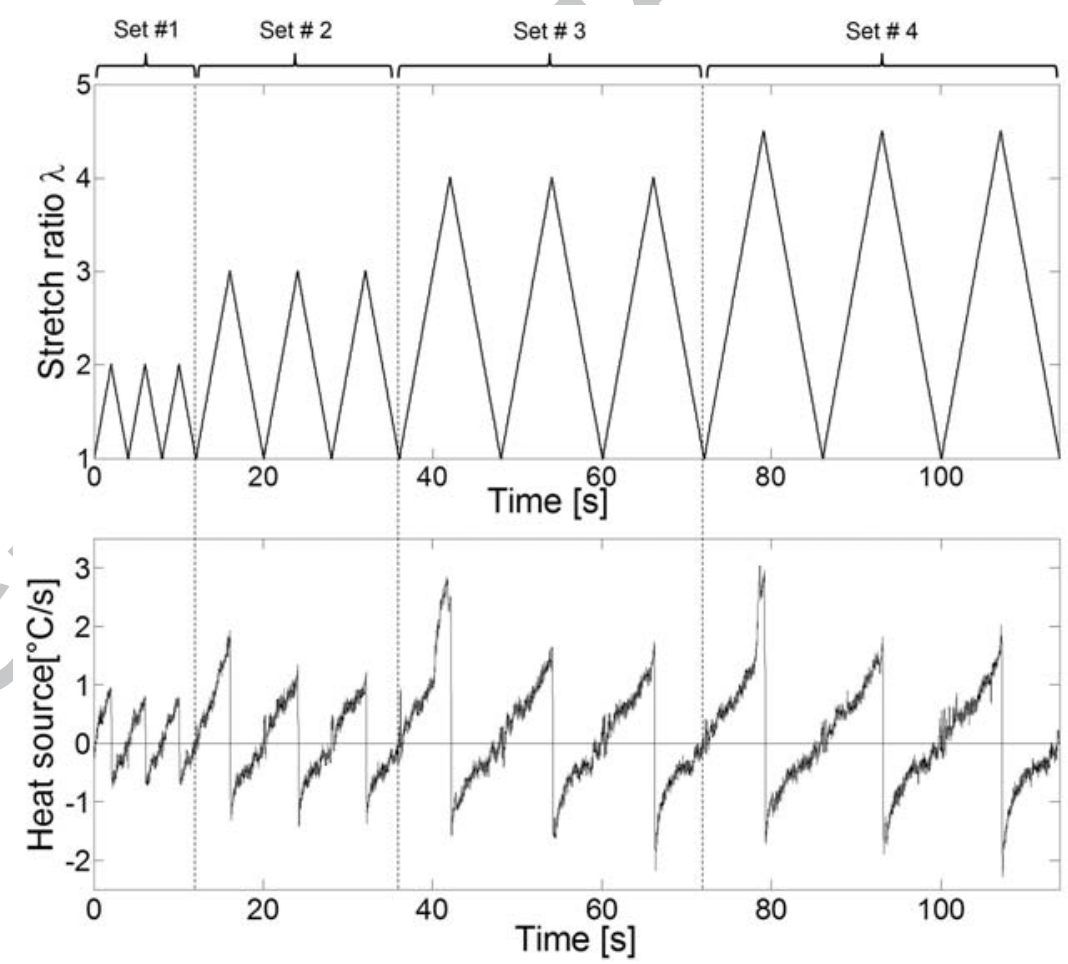

(b) SBR50

Fig. 3. Heat source evolution 


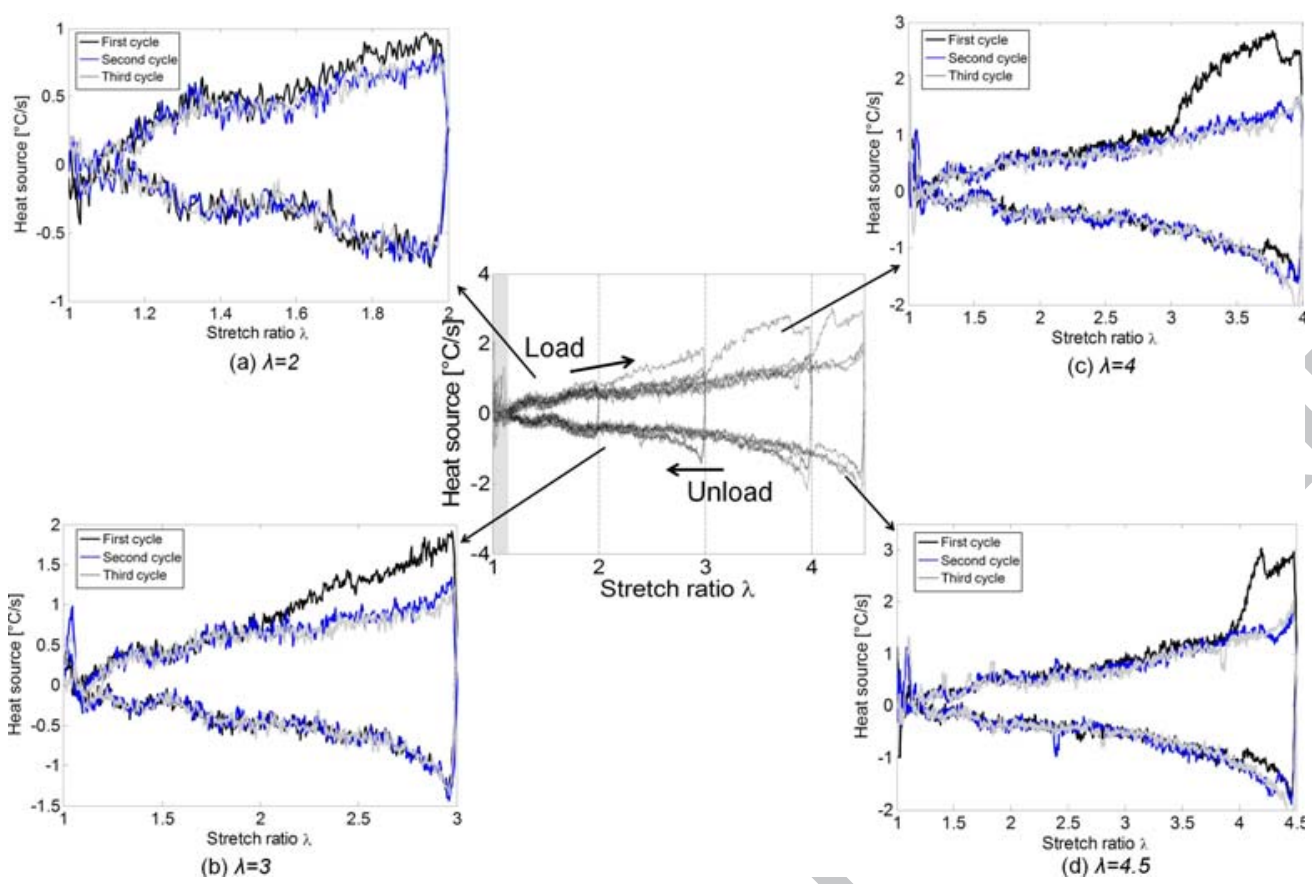

Fig. 4. Calorimetrical response obtained with SBR50 for the four maximum stretch ratios tested: $\lambda_{1}=2($ Figure $4(\mathrm{a})), \lambda_{2}=3$ (Figure $\left.4(\mathrm{~b})\right), \lambda_{3}=4$ (Figure $\left.4(\mathrm{c})\right)$ and $\lambda_{4}=4.5($ Figure $4(\mathrm{~d}))$

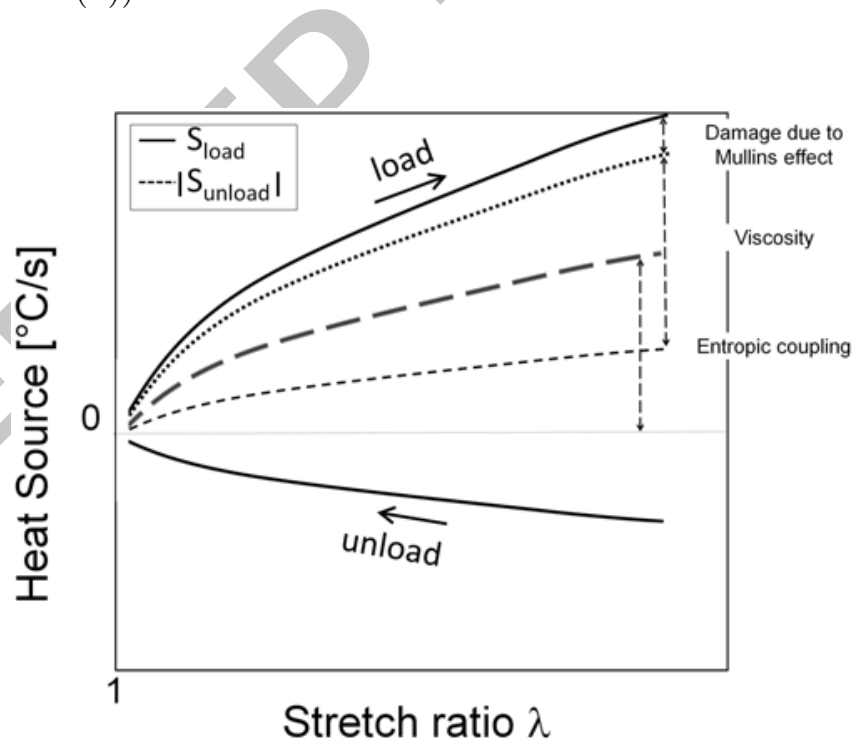

Fig. 5. Schematic evolution: heat source versus stretch ratio for entropic behaviour with the Mullins effect and viscosity 




Fig. 6. Calorimetric response obtained with NR50 for the last two maximum stretch ratios tested: $\lambda_{3}=4($ Figure $6(\mathrm{a}))$ and $\lambda_{4}=6($ Figure $6(\mathrm{~b}))$ 



Fig. 7. Beginning of the crystallization phenomenon in both mechanical and calorimetrical response 


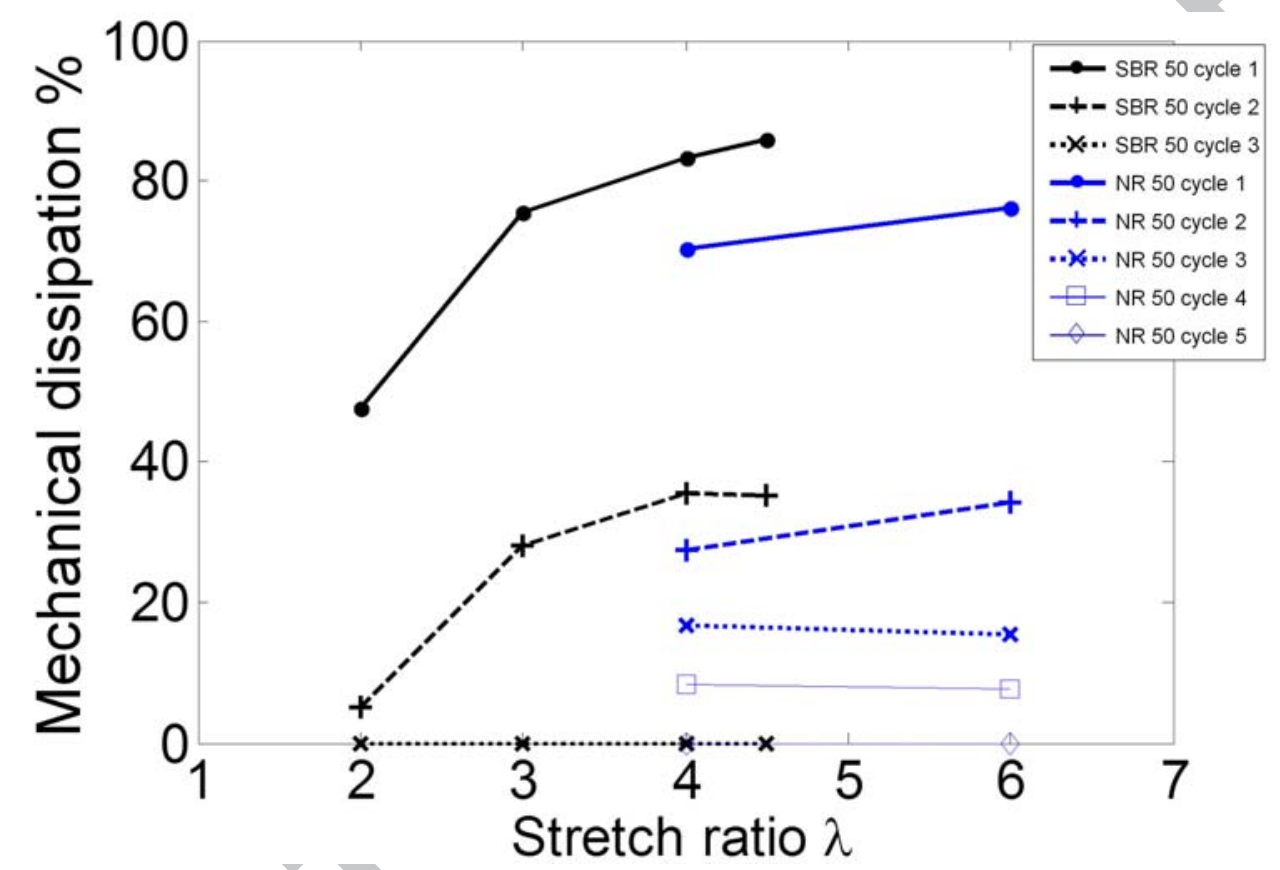

Fig. 8. Mechanical dissipation in percent for each cycle versus the maximum applied stretch ratio in filled SBR and NR 
New elements concerning the Mullins effect: a thermomechanical analysis

J. R. Samaca Martinez, J.-B. Le Cam, X. Balandraud, E. Toussaint and J. Caillard
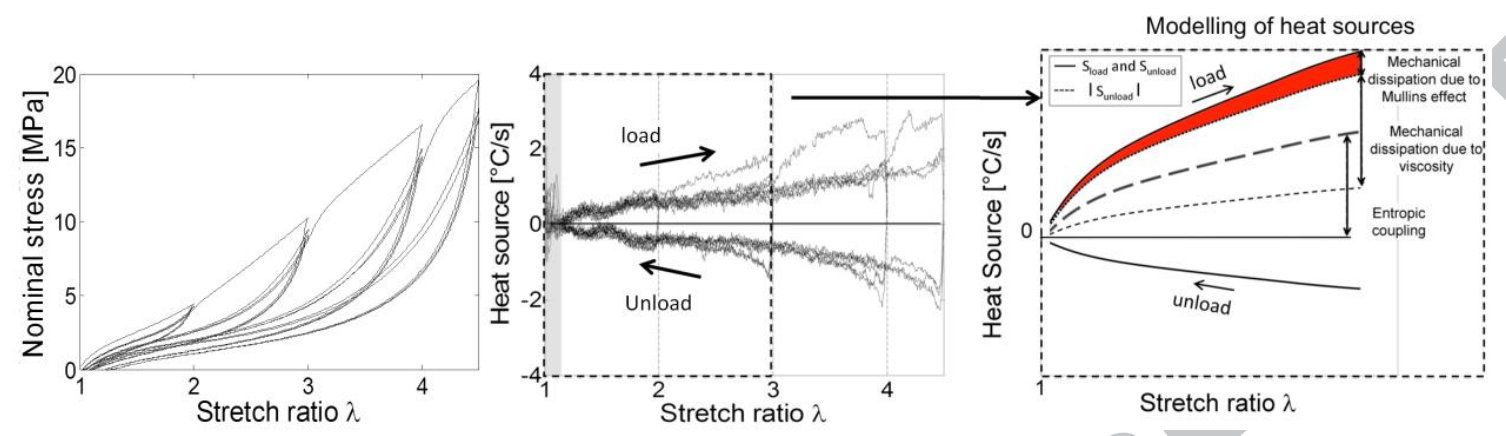
Filled styrene butadiene and natural rubbers are tested under cyclic uniaxial loading.

Temperature measurements are performed using infrared thermography.

Calorimetric response of both materials is characterized during stress softening.

Mechanical dissipation due to Mullins effect is determined.

Results provide the first database for thermomechanical modeling of Mullins effect. 